\title{
Calcium channel structures come of age
}

\author{
Cell Research (2016) 26:1271-1272. doi:10.1038/cr.2016.126; published online 1 November 2016
}

\begin{abstract}
A near-atomic resolution structure of a mammalian voltage-gated calcium channel $\left(\mathrm{Ca}_{\mathrm{v}}\right)$ has been determined. This first fully-assembled $\mathrm{Ca}_{\mathrm{v}}$ structure illuminates mechanisms of $\mathrm{Ca}_{\mathrm{v}}$ properties and functions and ushers in a new era in $\mathrm{Ca}_{\mathrm{v}}$ research and beyond.
\end{abstract}

Voltage-gated calcium channels $\left(\mathrm{Ca}_{\mathrm{v}} \mathrm{s}\right)$ control movement, heartbeat, hormone secretion and brain activity. Malfunction of $\mathrm{Ca}_{\mathrm{v}} \mathrm{s}$ due to gene mutations or dysregulation causes cardiovascular, sensory and neurological diseases [1]. $\mathrm{Ca}_{\mathrm{v}} \mathrm{s}$ are targets of several blockbuster drugs [1]. What do $\mathrm{Ca}_{\mathrm{v}} \mathrm{s}$ look like? How do the different molecular components of $\mathrm{Ca}_{\mathrm{v}}$ intermingle? What makes a calcium channel a calcium channel? How do $\mathrm{Ca}_{v}$ s gate (i.e., open, close and inactivate)? Where and how do $\mathrm{Ca}_{\mathrm{v}}$ drugs bind? How do diseasecausing mutations alter $\mathrm{Ca}_{\mathrm{v}}$ structure and function? A near-atomic resolution structure of a prototypical mammalian $\mathrm{Ca}_{\mathrm{v}}$ obtained by $\mathrm{Wu}$ and colleagues and published recently in Nature [2] (Figure 1) provides answers or clues to these interesting, important and long-pursued questions.

$\mathrm{Ca}_{\mathrm{v}} \mathrm{s}$ belong to the superfamily of voltage-gated ion channels. The socalled high-voltage activated $\mathrm{Ca}_{\mathrm{v}} \mathrm{s}$ are composed of a pore-forming $\alpha 1$-subunit and auxiliary $\alpha 2 \delta-, \beta$ - and, in the case of the $\mathrm{Ca}_{\mathrm{v}} 1.1$ complex elucidated by Wu et al., $\gamma$-subunits (Figure 1A). The a1-subunit, which contains four homologous but nonidentical repeats, dictates the major biophysical and pharmacological properties of $\mathrm{Ca}_{\mathrm{v}} \mathrm{s}$, but the auxiliary subunits play key roles in regulating channel gating and traffick- ing $[1,3,4]$.

Crystal structures of $\mathrm{Ca}_{\mathrm{v}}$ fragments in complex with calmodulin and of $\beta$-subunit in complex with its binding site in the $\alpha 1$-subunit (named the $\alpha$-interacting domain, or AID) had been obtained some years ago [3,5] (Figure 1A), and a crystal structure of $\mathrm{Ca}_{\mathrm{v}} \mathrm{Ab}$, an engineered model bacterial $\mathrm{Ca}_{\mathrm{v}}$ formed by four identical single-repeat subunits, has been determined recently [6]. However, before the recent game-changing breakthrough in single-particle cryoelectron microscopy (cryo-EM) [7], high-resolution structures of mammalian $\mathrm{Ca}_{\mathrm{v}} \mathrm{s}$ seemed unachievable in the next 10 or even 20 years. This is not only because mammalian $\mathrm{Ca}_{v} \mathrm{~s}$ are composed of multiple subunits, but also because the multi-repeat $\alpha 1$-subunit is large (190-280 kDa) and contains numerous transmembrane helices and several long flexible regions, making them intractable by X-ray crystallography. Moreover, obtaining sufficient amount of pure, homogenous and fully-assembled $\mathrm{Ca}_{\mathrm{v}}$ proteins suitable for X-ray crystallography was a daunting challenge.

Wu and colleagues solved the structure of the full $\mathrm{Ca}_{\mathrm{v}} 1.1$ complex from the rabbit skeletal muscle by using singleparticle cryo-EM, which circumvents many of the hurdles confronting X-ray crystallography. The authors used a clever strategy to obtain and purify the native $\mathrm{Ca}_{\mathrm{v}} 1.1$ complex by replacing the endogenous $\beta 1 \mathrm{a}$ with a recombinant tagged $\beta 1 \mathrm{a}$ and taking advantage of the reversibility of the $\alpha 1 / \beta$ interaction [3]. A large dataset and sophisticated data processing aided the determination of the final $3.6 \AA$-resolution structure, improving upon an earlier lower-resolution structure obtained by the same group [8].

The new structure provides unparalleled insights into the mechanisms of $\mathrm{Ca}_{\mathrm{v}}$ assembly, ion permeation, gating and regulation. The structure confirms the pentameric architecture of $\mathrm{Ca}_{\mathrm{v}} 1.1$ (Figure 1B). The four repeats of $\alpha 1$ enclose clockwise to form the asymmetric main body of the channel, with an ion conduction pore in the center. The intracellular end of S6, which forms the inner pore, is tightly closed. This, coupled with the 'up' position of the voltage-sensing S4 helix, suggests that the channel is in an inactivated state. The ion selectivity filter is formed by a ring of carboxylate side chains of the signature 'EEEE locus' and two rings of backbone carbonyl oxygens. This design of employing a combination of negatively charged side chains and main-chain carbonyls to coordinate ions is shared by other calcium-conducting channels, including $\mathrm{Ca}_{\mathrm{v}} \mathrm{Ab}$ [6], TRPV1 [7] and the type I ryanodine receptor [9].

The $\mathrm{Ca}_{\mathrm{v}} 1.1$ structure reveals how the auxiliary subunits interface with the $\alpha 1$ subunit (Figure 1B). The $\alpha 2 \delta$-subunit is shown to be cleaved, disulfide-bonded, glycosylated and anchored to the membrane, as previously described [4], with the relevant site(s) identified. $\alpha 2 \delta$ binds several extracellular loops of $\alpha 1$, the amino acid sequences of which diverge among different $\alpha 1 \mathrm{~s}$; thus, the strength of the $\alpha 1 / \alpha 2 \delta$ interaction likely varies in different $\mathrm{Ca}_{\mathrm{v}} \mathrm{s}$. A striking revelation is that $\alpha 2 \delta$ protrudes far into the extracellular space, raising questions of whether it interacts with extracellular matrix proteins and/or other cell surface proteins and how such interac- 

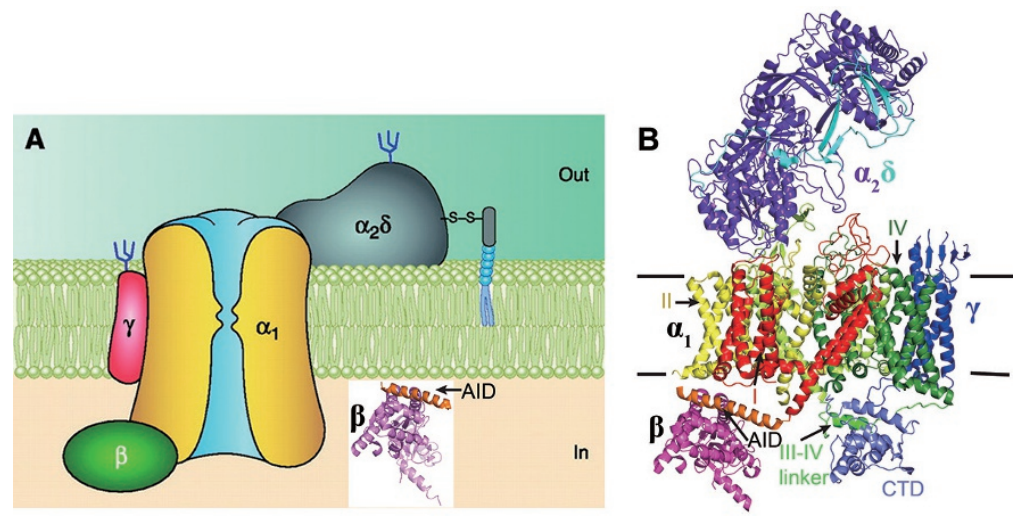

Figure 1 Calcium channel structures - then and now. (A) Schematic of a $\mathrm{Ca}_{\mathrm{v}}$ complex from a 2010 review [3]. This type of cartoon has been used to depict $\mathrm{Ca}_{\mathrm{v}} \mathrm{s}$ in the last 30 years. The inset shows a structure of a $\beta$-subunit bound with the AID, obtained in 2004 (PDB code: 1VYT). (B) Cryo-EM structure of the rabbit skeletal muscle $\mathrm{Ca}_{\mathrm{v}} 1.1$ complex (PDB code: 5GJV) determined by Wu and colleagues in 2016 [2]. The different subunits are differentially colored, so are the four repeats, the AID, the III-IV linker and the proximal C-terminal domain (CTD) of the $\alpha 1$-subunit.

tions alter $\mathrm{Ca}_{\mathrm{v}}$ functions. The $\beta$-subunit binds the AID in the same manner as it does in isolated $\beta$ /AID complexes. However, while the AID was previously envisioned to form a continuous $\alpha$-helix with S6 of repeat I (IS6) [3, 5], the $\mathrm{Ca}_{v} 1.1$ structure shows that the AID helix is discontinuous with IS6 and runs nearly parallel to the membrane. This orientation places some $\beta$-subunit regions involved in gating modulation away from the transmembrane domains, suggesting that they may interact with $\alpha 1$ regions unresolved in the structure. The $\gamma$-subunit interacts primarily with the voltage-sensing domain of repeat IV, explaining its modulatory effect on gating [3]. Notably, the linker between repeats III and IV (the III-IV linker) of $\alpha 1$ interacts with the proximal Cterminal domain of $\alpha 1$, an interaction that may also modulate gating.

The determination of the first mam- malian $\mathrm{Ca}_{\mathrm{v}}$ structure marks a watershed in the studies of $\mathrm{Ca}_{\mathrm{v}}$ structure-function and $\mathrm{Ca}_{\mathrm{v}}$-centric physiology, pharmacology and channelopathy. It will surely spur structural elucidation of other $\mathrm{Ca}_{\mathrm{v}} \mathrm{S}$ and investigation of the structural basis of $\mathrm{Ca}_{\mathrm{v}}$ drug actions. Among these drugs, dihydropyridines (e.g., amlodipine), phenylalkylamines (e.g., verapamil) and benzothiazepines (e.g., diltiazem) are used to treat hypertension, angina pectoris and cardiac arrhythmias and target the $\alpha 1$-subunit of $\mathrm{Ca}_{v} 1.2$, whereas gabapentin and pregabalin are used to treat epilepsy and neuropathic pain and target the $\alpha 2 \delta$-subunit of $\mathrm{Ca}_{\mathrm{v}} \mathrm{s}$ in the nervous system $[1,4]$. The binding sites of dihydropyridines and phenylalkylamines have been identified recently in $\mathrm{Ca}_{\mathrm{v}} \mathrm{Ab}$ [10], but whether these drugs bind in the same way in $\mathrm{Ca}_{\mathrm{v}} 1.2$ remains to be determined. Based on the $\mathrm{Ca}_{\mathrm{v}} 1.1$ structure, more accurate homology structure models of other $\mathrm{Ca}_{\mathrm{v}} \mathrm{s}$ can now be generated. By the same token, the locations of numerous disease-causing single amino acid missense mutations can now be mapped on the $\mathrm{Ca}_{\mathrm{v}} 1.1$ structure and their effects on $\mathrm{Ca}_{\mathrm{v}}$ structure/ function can now be more precisely investigated. With the continuing rapid advance in structure biology, there is good reason to be optimistic that the structures of various macromolecular $\mathrm{Ca}_{\mathrm{v}}$ complexes will be solved in the coming years, which will inform the molecular mechanisms of not only $\mathrm{Ca}_{\mathrm{v}}$ functions but also excitation-contraction coupling, excitation-transcription coupling and excitation-secretion coupling.

Jian Yang ${ }^{1}$

${ }^{1}$ Department of Biological Sciences, Columbia University, New York, NY 10027, USA

Correspondence: Jian Yang

E-mail: jy160@columbia.edu

\section{References}

1 Zamponi GW, Striessnig J, Koschak A, et al. Pharmacol Rev 2015; 67:821-870.

2 Wu J, Yan Z, Li Z, et al. Nature 2016; 537:191-196.

3 Buraei Z, Yang J. Physiol Rev 2010; 90:1461-1506.

4 Dolphin AC. J Physiol 2016; 594:53695390.

5 Minor DL Jr, Findeisen F. Channels 2010; 4:459-474.

6 Tang L, Gamal El-Din TM, Payandeh J, et al. Nature 2014; 505:56-61.

7 Liao M, Cao E, Julius D, et al. Nature 2013; 504:107-112.

8 Wu J, Yan Z, Li Z, et al. Science 2015; 350: $\operatorname{aad} 2395$.

9 Yan Z, Bai XC, Yan C, et al. Nature 2015; 517:50-55.

10 Tang L, Gamal El-Din TM, Swanson TM, et al. Nature 2016; 537:117-121. 